\title{
Medication adherence in HIV-positive pregnant women on antiretroviral therapy attending antenatal clinics in Ado metropolis, south-west Nigeria: A multicentre study
}

\author{
O P Aduloju, ${ }^{1}$ MBBS, MPH, FWACS; T Aduloju, ${ }^{2}$ RN, RM, BEd, MSW; I P Ade-Ojo, ${ }^{1}$ MBBS, FWACS, FMCOG; \\ A A Akintayo, ${ }^{1} \mathrm{MBBS}$, FWACS \\ ${ }^{1}$ Department of Obstetrics and Gynaecology, Ekiti State University, Ado-Ekiti, Nigeria \\ ${ }^{2}$ Department of Medical Social Services, Ekiti State University Teaching Hospital, Ado-Ekiti, Nigeria
}

Corresponding author: O P Aduloju (peter.aduloju@yahoo.com)

Background. Adherence to antiretroviral therapy (ART) and optimal viral suppression are crucial to the prevention of mother-to-child transmission (PMTCT) of HIV/AIDS.

Objective. To determine adherence to ART and associated factors in Ado-Ekiti, Nigeria.

Methods. A cross-sectional multicentre study was conducted among 170 HIV-positive pregnant women attending antenatal clinics of Ekiti State University Teaching Hospital and the Comprehensive Health Centre in Ado-Ekiti. Data collected using a semi-structured questionnaire were analysed with SPSS. Descriptive statistics, univariate and logistic regression were performed to determine factors associated with good adherence.

Results. Using the pill count method and the Morisky Medication Adherence Scale-8 (MMAS-8), the prevalence of good adherence was $73.5 \%$ and $75.3 \%$, respectively. Women with higher education were three times more likely to practise good adherence than those with little or no formal education (adjusted odds ratio (aOR) $=3.03$; 95\% confidence interval (CI) $1.23-5.79$; $p=0.043$ ) and those employed were four times more likely to practise good adherence (aOR=4.13; 95\% CI $1.83-8.15 ; p=0.02$ ). Also, partner disclosure, treatment support and use of ARVs for prevention of mother-to-child transmission (PMTCT) were indications of women three times more likely to practise good adherence ( $(\mathrm{aOR}=2.53 ; 95 \% \mathrm{CI} 0.99-5.80 ; p=0.035) ;(\mathrm{aOR}=2.15 ; 95 \% \mathrm{CI} 0.77-4.15 ; p=0.014)$ and $(\mathrm{aOR}=3.15 ; 95 \% \mathrm{CI} 0.93$ - $6.21 ; p=0.035)$ ). Forgetfulness, busy schedule and stigmatisation were reasons given for non-adherence.

Conclusions. The majority of the women had good adherence. However, counselling on adherence and partner disclosure should be sustained to ensure full benefits of PMTCT.

S Afr J Obstet Gynaecol 2020;26(2):65-70. https://doi.org/10.7196/SAJOG.2020.v26i2.1611

Prevention of mother-to-child transmission (PMTCT) is a pillar in the elimination of vertical transmission of HIV, with considerable efforts made towards appropriate interventions. ${ }^{[1]}$ In 2017, 180 000 children were newly infected with HIV, with $88 \%$ in sub-Saharan Africa and the majority of whom infected through mother-to-child transmission (MTCT). ${ }^{[2]}$ Nigeria has the highest rate of MTCT of HIV globally, despite the low prevalence of HIV, with 37000 children newly infected with HIV in 2017. ${ }^{[3]}$ The risk of MTCT ranges between $25 \%$ and $48 \%$ without any intervention, while this risk is reduced to $<2 \%$ and $5 \%$ with appropriate interventions in non-breastfeeding and breastfeeding mothers, respectively. Most MTCT occurs in the intrapartum period. ${ }^{[4,5]}$

The goal of highly active antiretroviral therapy (HAART) in PMTCT is to achieve maximal viral suppression so as to reduce vertical transmission and to provide prophylaxis for the baby. ${ }^{[6]}$ Successful and positive impact of antiretroviral therapy (ART) requires high rates of adherence. There is a clear relationship between adherence to antiretroviral (ARV) drug treatment, viral load suppression, acquired drug resistance and treatment failure. ${ }^{[6]}$ Adequate adherence to the prescribed ARV medications is essential to achieving maximal viral suppression necessary to prevent MTCT. Adherence rates exceeding $95 \%$ are necessary, in order to maximise the benefits of ART. Higher levels of drug adherence are associated with improved virological, immunological and clinical outcome. ${ }^{[7]}$

Adherence to HAART is complex, requiring patients to remember multiple medications and dosing schedules. Patient failure to follow the ART regimen can lead to the development of treatment-resistant strains and poorer health outcomes. ${ }^{[8,9]}$ Several studies done in Nigeria have examined adherence to ART among HIV-positive patients, ${ }^{[10-12]}$ with very few among HIV-positive pregnant women. ${ }^{[6,13]}$ Studies on adherence to ART among HIV-positive pregnant patients by Igwegbe et al. ${ }^{[6]}$ in south-eastern Nigeria and Ekama et al ${ }^{[13]}$ in south-western Nigeria reported prevalence rates of $80.6 \%$ and $78.3 \%$, respectively. Fear of stigmatisation, discrimination, forgetfulness, feeling of good health, living far away from the hospital and lack of access to transportation, pill burden and side-effects of the drugs were some of the factors found to be associated with suboptimal adherence. ${ }^{[6,13-15]}$

There has been no study in Ekiti State on adherence to ARV medication among HIV-positive pregnant women. Therefore, this study was conducted to determine adherence to ART and the associated factors among HIV-positive pregnant women attending antenatal clinics in Ado-Ekiti, south-western Nigeria. Findings from this study will help to influence policy that will strengthen PMTCT services in Ekiti State. 


\section{Methods}

This was a multicentre cross-sectional study conducted among HIVpositive pregnant women attending antenatal clinics in Ekiti State University Teaching Hospital (EKSUTH) and the Comprehensive Health Centre (CHC), both located in Ado-Ekiti, south-western Nigeria between 1 February 2018 and 31 January 2020. Ado-Ekiti is the capital of Ekiti State with a land area of $293 \mathrm{~km}^{2}$ and a population of 308621 according to the 2006 population census. The majority of inhabitants are Christians and are civil servants, farmers and artisans.

EKSUTH and CHC offer free comprehensive HIV/AIDS services, including PMTCT services. These services are under the sponsorship of the US President's Emergency Plan for AIDS Relief (PEPFAR) through AIDS Prevention in Nigeria (APIN), a nongovernmental organisation and Ekiti State Agency for Control of AIDS. Following status determination, every HIV-positive pregnant woman is started on lifelong ART with a single fixeddose combination tablet of efavirenz, emcitritabine and tenofovir disoproxil fumarate (Atripla), regardless of their clinical status or CD4 count. HIV-positive pregnant women will have at least one CD4 count and viral load estimate done before delivery of their baby to determine whether the HIV-exposed infant is at high risk and eligible for enhanced ART prophylaxis. ${ }^{[16]}$ Prior to ART commencement, HIV-positive pregnant women receive adherence counselling, provided by nurses and midwives in the antenatal clinic, and ongoing adherence counselling is provided at every refill visit by trained adherence counsellors.

The sample size was calculated using the formula for single proportion. Using the prevalence of $10.8 \%$ among pregnant women from a previous study in Nigeria, ${ }^{[14]}$ a $95 \%$ confidence interval (CI), $5 \%$ margin of error and $10 \%$ contingency for non-respondents, a sample size of 164 was calculated.

All HIV-positive pregnant women with known gestational age attending an antenatal clinic in the study centres, who had been on ARV drugs for at least 3 months prior to the study and gave consent to participate in the study, were included. Those who had not been on ART for up to 3 months and who withheld consent were excluded. The eligible women at both health facilities were counselled about the study by trained research assistants, and those who expressed their willingness to participate were recruited consecutively after signing the informed consent.

Data were collected from the women using a pretested interviewer-administered questionnaire divided into two parts. The first part enquired about sociodemographic characteristics, such as age, parity, educational and occupational status (of the women and their spouses), religion, marital status and socioeconomic status (assessed by adding scores of the women's education level and their husbands' occupation; social classes I and II were categorised as high class, class III as middle class and classes IV and V as low class as described by Olusanya et al. $\left.{ }^{[17]}\right)$. The second part assessed knowledge of HIV, stigmatisation, partner disclosure, adherence to ARV drugs, use of isoniazid preventive therapy (IPT) and factors that encouraged adherence or non-adherence. Their CD4 count and viral load were extracted from their case records.

Adherence to ARV medication was assessed using the pill count method and the modified Morisky Medication Adherence Scale- 8 (MMAS-8). Adherence using the pill count method was ascertained by counting the number of remaining pills in relation to the total number of prescribed doses during the last visit. Adherence status was termed 'good' when study participants had taken at least $95 \%$ of the total drugs at the prescribed dosing interval, while 'poor' adherence status was determined by missing at least $5 \%$ of all the doses over the period of a month. The MMAS- 8 is an 8 -item validated self-reported questionnaire used in assessing adherence of patients to medication. ${ }^{[18]}$ It examines the knowledge and motivation levels of patients in respect of adherence to their medication. The first seven items on the scale have a binary response (Yes=1, $\mathrm{No}=0$ ) indicating adherent or non-adherent while the eighth item is answered using a 5-point Likert scale - never; almost never; sometimes; often and always - expressing how often a patient misses taking medication. Adherence level using MMAS- 8 was graded in this study as high adherence with a score of 0 , medium adherence with a score of 1 and 2, and poor adherence with a score above 2 .

The data collected were analysed using the Statistical Package for Social Sciences (SPSS) software, version 22 (IBM Corp., USA). Categorical variables were presented in frequency and percentages while continuous variables were expressed in mean and standard deviation (SD). The $\chi^{2}$ test was used to test for significance for categorical variables and Student's $t$-test and one-way analysis of variance (ANOVA) for continuous variables. Logistic regression analysis was done to determine factors associated with good adherence among the women, using odds ratios and 95\% CIs. A $p$-value $<0.05$ was considered statistically significant.

The study was approved by the Ethics and Research Committee of Ekiti State Primary Health Care Development Agency and Ekiti State University Teaching Hospital. The women were adequately informed about the study and written informed consent was obtained from them. The data collected were made anonymous and they were at liberty to withdraw from further participation without affecting their care.

\section{Results}

A total of $170 \mathrm{HIV}$-positive pregnant women participated in the study. The study showed that 125 (73.5\%) women had good adherence (taking at least $95 \%$ of the total drugs at the prescribed dosing interval) using the pill count method while 128 (75.3\%) women had a score 2 and below using the MMAS- 8 . The overall percentage agreement between pill count and self-reported adherence using MMAS- 8 was $99.6 \%$ with a kappa statistics of 0.99 $(p<0.001)$.

The mean (SD) age of the women was 29.82 (5.87) years, mean (SD) gestational age was 29.08 (4.08) weeks, mean (SD) duration of ART use was 3.30 (1.56) years and the median parity and interquartile range were 2 , respectively. The majority of women were married (75.9\%), had at least primary education (75.3\%), were gainfully employed $(82.9 \%)$ and dwelt in the urban area. Other sociodemographic characteristics of the women are shown in Table 1.

About three-fifths of the women had disclosed their status to their partners (58.8\%), displayed good knowledge about HIV (61.8\%), had treatment support (58.2\%) and had CD4 counts of $350-450$ cells $/ \mathrm{mm}^{3}(61.8 \%)$. More than two-thirds of the women agreed that ART can prevent MTCT of HIV (67.1\%) and had suppressed viral loads (70.0\%). Less than half of the women had had PMTCT exposure before $(45.9 \%)$ and had experienced stigmatisation as a result of their status $(47.6 \%)$ (Table 2$)$.

Table 3 shows that on univariate analysis, the parity $(p=0.026)$, marital status ( $p=0.001)$, education $(p=0.005)$, occupation $(p=0.001)$, place of residence $(p=0.001)$ and the mean CD4 counts $(p=0.001)$ 
Table 1. Sociodemographic characteristics of the women in the study $(N=170)$

\begin{tabular}{ll}
\hline Variable & $\boldsymbol{n}(\%)^{\star}$ \\
\hline Age (years), mean (SD) & $29.82(5.87)$ \\
Parity, mean (SD) & $1.77(1.03)$ \\
Gestational age (weeks), mean (SD) & $29.08(4.08)$ \\
Duration of ART use (years), mean (SD) & $3.30(1.56)$ \\
Marital status & \\
$\quad$ Married & $129(75.9)$ \\
Single & $22(12.9)$ \\
Widowed & $10(5.9)$ \\
Divorced & $9(5.3)$ \\
Education & \\
None & $42(24.7)$ \\
$\quad$ Primary & $40(23.5)$ \\
Secondary & $38(22.4)$ \\
Tertiary & $50(29.4)$ \\
Occupation & \\
Unemployed & $29(17.1)$ \\
Self-employed & $32(18.8)$ \\
Privately employed & $31(18.2)$ \\
Government employed & $78(45.9)$ \\
Religion & \\
Christianity & $107(62.9)$ \\
Islam & $63(37.1)$ \\
Place of residence & \\
Rural & $56(32.9)$ \\
Urban & $114(67.1)$ \\
Social class & \\
Low & $75(44.1)$ \\
Middle & $43(25.3)$ \\
High & $32(30.6)$ \\
*Unless otherwise specified. & \\
& \\
\hline
\end{tabular}

of the women were significantly associated with good adherence to medication while the age, religion, ethnicity and social class of the women were not significantly associated $(p>0.05)$. Also, there was no significant difference in the mean age, parity, gestational age and duration of ARV drugs use among the women with good or poor medication adherence $(p>0.05)$.

The univariate analysis of the clinical factors affecting adherence showed that knowledge of HIV $(p=0.001)$, status disclosure to partners $(p=0.022)$, previous PMTCT $(p=0.049)$, use of ART for PMTCT $(p=0.001)$, treatment support by partners $(p=0.001)$ and low risk of stigmatisation $(p=0.001)$ were significantly associated with good medication adherence while duration of ART use was not significantly associated with good adherence, $p>0.05$ (Table 4 ).

Table 5 shows that post-primary education $(p=0.043)$, being employed $(p=0.020)$, disclosure of status to partners $(p=0.035)$, use of ART for PMTCT ( $p=0.035)$ and treatment support by partner and relatives $(p=0.014)$ were significant determinants of good adherence on regression analysis of the significant variables from univariate analysis.

\section{Discussion}

The use of ARV drugs has been established as one of the effective strategies in the reduction of MTCT of HIV infection. ${ }^{[13]}$ It has been shown that zero MTCT of HIV is achievable when the viral load is undetectable, and this can only be achieved with optimal
Table 2. Clinical characteristics of the women in the study

\begin{tabular}{|c|c|}
\hline Variable & $n(\%)$ \\
\hline \multicolumn{2}{|l|}{ Adherence status (pill count) } \\
\hline No & $45(26.5)$ \\
\hline Yes & $125(73.5)$ \\
\hline \multicolumn{2}{|l|}{ Adherence level } \\
\hline Low & $42(24.7)$ \\
\hline Moderate & $51(30.0)$ \\
\hline High & $77(45.3)$ \\
\hline \multicolumn{2}{|l|}{ Partner disclosure } \\
\hline No & $70(41.2)$ \\
\hline Yes & $100(58.8)$ \\
\hline \multicolumn{2}{|l|}{ Previous PMTCT } \\
\hline No & $92(54.1)$ \\
\hline Yes & $78(45.9)$ \\
\hline \multicolumn{2}{|l|}{ Knowledge of HIV } \\
\hline Poor & $65(38.2)$ \\
\hline Good & $105(61.8)$ \\
\hline \multicolumn{2}{|l|}{ Stigmatisation } \\
\hline No & $89(52.4)$ \\
\hline Yes & $81(47.6)$ \\
\hline \multicolumn{2}{|l|}{ IPT use } \\
\hline No & $13(7.6)$ \\
\hline Yes & $157(92.4)$ \\
\hline \multicolumn{2}{|l|}{ Treatment support } \\
\hline No & $71(41.8)$ \\
\hline Yes & $99(58.2)$ \\
\hline \multicolumn{2}{|l|}{ РМтст } \\
\hline Yes & $56(32.9)$ \\
\hline No & $114(67.1)$ \\
\hline \multicolumn{2}{|l|}{ Viral loads } \\
\hline Unsuppressed & $51(30.0)$ \\
\hline Suppressed & $119(70.0)$ \\
\hline \multicolumn{2}{|l|}{$\mathrm{CD} 4$ counts $\left(\mathrm{cell} / \mathrm{mm}^{3}\right)$} \\
\hline$<350$ & $31(18.2)$ \\
\hline $350-450$ & $105(61.8)$ \\
\hline$>450$ & $34(20.0)$ \\
\hline \multicolumn{2}{|c|}{ Reasons for adherence to drugs $(n=125)^{*}$} \\
\hline To protect my unborn child & $125(100.0)$ \\
\hline To stay alive and live healthy & $111(88.8)$ \\
\hline Previous PMTCT experience & $69(55.2)$ \\
\hline \multicolumn{2}{|c|}{ Reasons for non-adherence to drugs $(n=45)^{*}$} \\
\hline Feeling better & $41(91.1)$ \\
\hline Forgetfulness & $33(73.3)$ \\
\hline Busy work schedule & $31(68.9)$ \\
\hline Side-effects of the drugs & $27(60.0)$ \\
\hline Fear of stigmatiation & $25(55.6)$ \\
\hline
\end{tabular}

adherence to ARV drugs. Hence, ART adherence of at least $95 \%$ of the drugs taken at prescribed dosing intervals optimises outcome and minimises occurrence of viral resistance. ${ }^{[19]}$ The adherence prevalence rate found among the HIV-positive pregnant women involved in this study was $73.5 \%$ (the pill count method) and this is comparable to the finding reported from south-east Nigeria by Igwegbe et al. ${ }^{[6]}$ However, this rate is higher than figures reported from south-west Nigeria and south Nigeria by Olowookere et al. ${ }^{[10]}$ and Omonaiye et al. ${ }^{[2]}$ respectively, but lower than those reported 
RESEARCH

Table 3. Sociodemographic characteristics and adherence among HIV-positive pregnant women

\begin{tabular}{|c|c|c|c|}
\hline Variable & $\begin{array}{l}\text { Poor adherence } \\
n=45, n(\%)^{*}\end{array}$ & $\begin{array}{l}\text { Good adherence } \\
n=125, n(\%)^{*}\end{array}$ & $p$-value \\
\hline \multicolumn{4}{|l|}{ Age group (years) } \\
\hline$<20$ & $5(1.5)$ & $6(54.5)$ & 0.214 \\
\hline $20-35$ & $29(23.4)$ & $95(76.6)$ & \\
\hline$>35$ & $11(31.4)$ & $24(68.6)$ & \\
\hline \multicolumn{4}{|l|}{ Parity } \\
\hline 0 & $5(26.3)$ & $14(73.7)$ & $0.026^{\dagger}$ \\
\hline $1-2$ & $35(32.7)$ & $72(67.3)$ & \\
\hline$>2$ & $5(11.4)$ & $39(88.6)$ & \\
\hline \multicolumn{4}{|l|}{ Marital status } \\
\hline Married & $23(17.8)$ & $106(82.2)$ & $0.001^{\dagger}$ \\
\hline Single & $13(59.1)$ & $9(40.9)$ & \\
\hline Widowed & $5(50.0)$ & $5(50.0)$ & \\
\hline Divorced & $4(44.4)$ & $5(55.6)$ & \\
\hline \multicolumn{4}{|l|}{ Education (women) } \\
\hline None & $17(40.5)$ & $25(58.5)$ & $0.005^{\dagger}$ \\
\hline Primary & $14(35.0)$ & $26(65.0)$ & \\
\hline Secondary & $9(23.7)$ & $29(76.3)$ & \\
\hline Tertiary & $5(10.0)$ & $45(90.0)$ & \\
\hline \multicolumn{4}{|l|}{ Occupation (women) } \\
\hline Unemployed & $13(44.8)$ & $16(55.2)$ & $0.001^{\dagger}$ \\
\hline Self-employed & $9(28.1)$ & $23(71.9)$ & \\
\hline Privately employed & $15(48.4)$ & $16(51.6)$ & \\
\hline Government employed & $8(10.3)$ & $70(89.7)$ & \\
\hline \multicolumn{4}{|l|}{ Religion } \\
\hline Christianity & $23(21.5)$ & $84(78.5)$ & 0.055 \\
\hline Islam & $22(34.9)$ & $41(65.1)$ & \\
\hline \multicolumn{4}{|l|}{ Place of residence } \\
\hline Rural & $26(46.4)$ & $30(53.6)$ & $0.001^{\dagger}$ \\
\hline Urban & $19(16.7)$ & $95(83.3)$ & \\
\hline \multicolumn{4}{|l|}{ Social class } \\
\hline Low & $28(29.5)$ & $67(70.5)$ & 0.602 \\
\hline Middle & $10(23.3)$ & $33(76.7)$ & \\
\hline High & $7(21.9)$ & $25(78.1)$ & \\
\hline Age (years), mean (SD) & $30.42(5.95)$ & $29.74(5.86)$ & 0.508 \\
\hline Parity, mean (SD) & $1.58(0.89)$ & $1.84(1.07)$ & 0.144 \\
\hline Gestational age (weeks), mean (SD) & $28.27(3.90)$ & $29.38(4.12)$ & 0.118 \\
\hline Duration of ART use (years), mean (SD) & $3.10(1.62)$ & $3.38(1.54)$ & 0.310 \\
\hline CD4 counts (cells/mm $\left./ \mathrm{mm}^{3}\right)$, mean (SD) & $344.47(84.73)$ & 410.18 (61.19) & $0.001^{\dagger}$ \\
\hline
\end{tabular}

from Ethiopia by Shibabaw et al. ${ }^{[15]}$ and Zambia by Ngambi et al. ${ }^{[21]}$ The variation in the prevalence rate reported from these studies might be due to differences in the population of the respondents, as well as awareness and practice of PMTCT in the study areas, which were similarly expressed by Ekama et al. ${ }^{[13]}$ and Ng'ambi et al. ${ }^{[21]}$

Education and occupation of women, partner disclosure of HIV status, having treatment support and use of ARV drugs for PMTCT were the determinants of good medication adherence in this study. A higher level of education was found to be associated with increased likelihood of good medication adherence. Women with at least postprimary education were three times more likely to adhere to their medication regimen than those with no formal education. This finding is consistent with reports from previous studies done in Kano (northern Nigeria), Ethiopia and India. ${ }^{[12,15,22]}$ In these studies, women with low educational status had poor medication adherence and the authors emphasised the role of education in reproductive health. Education facilitates communication with health workers, engagement in beneficial health practices and use of maternal health services, including understanding of adherence counselling that would enhance optimal intake of ARV drugs. ${ }^{[23]}$ Employed women in this study had a higher rate of good adherence to ART. This is in agreement with findings of Shibabaw et al. ${ }^{[15]}$ where women with low monthly income were less adherent to their ARV drug regimen. Being employed financially empowers women and this assists them in taking critical decisions that will improve their health outcomes. ${ }^{[2]}$

Serostatus disclosure is an important factor in curtailing HIV spread, including PMTCT, and has been emphasised by the World Health Organization in its HIV counselling and testing protocol. ${ }^{[25]}$ In this study, women who disclosed their status to their partners showed better adherence. This was similarly reported in previous 
Table 4. Clinical characteristics and adherence among the women

\begin{tabular}{|c|c|c|c|}
\hline Variable & Poor adherence $n=45, n(\%)^{*}$ & Good adherence $n=125, n(\%)^{*}$ & $p$-value \\
\hline \multicolumn{4}{|c|}{ Knowledge of HIV } \\
\hline Poor & $38(58.5)$ & $27(41.5)$ & $0.001^{\dagger}$ \\
\hline Good & $7(6.7)$ & $98(93.3)$ & \\
\hline \multicolumn{4}{|c|}{ Partner disclosure } \\
\hline No & $26(36.6)$ & $45(63.4)$ & $0.022^{\dagger}$ \\
\hline Yes & $19(19.2)$ & $80(80.8)$ & \\
\hline \multicolumn{4}{|l|}{ РMTCT } \\
\hline No & $25(44.6)$ & $31(55.4)$ & $0.001^{\dagger}$ \\
\hline Yes & $20(17.5)$ & $94(82.4)$ & \\
\hline \multicolumn{4}{|c|}{ Previous PMTCT } \\
\hline No & $30(32.6)$ & $62(67.4)$ & $0.049^{\dagger}$ \\
\hline Yes & $15(19.2)$ & $63(80.8)$ & \\
\hline \multicolumn{4}{|c|}{ Stigmatisation } \\
\hline No & $10(11.2)$ & $79(88.8)$ & $0.001^{\dagger}$ \\
\hline Yes & $35(43.2)$ & $46(56.8)$ & \\
\hline \multicolumn{4}{|c|}{ Treatment support } \\
\hline No & $29(40.8)$ & $42(59.2)$ & $0.001^{\dagger}$ \\
\hline Yes & $16(16.2)$ & $83(83.8)$ & \\
\hline \multicolumn{4}{|c|}{ ART duration (years) } \\
\hline$<3$ & $17(30.9)$ & $38(69.1)$ & 0.234 \\
\hline$\geq 3$ & $28(24.3)$ & $87(75.7)$ & \\
\hline
\end{tabular}

Table 5. Logistic regression analysis of factors associated with medication adherence among HIV-positive pregnant women

\begin{tabular}{|c|c|c|}
\hline Variable & aOR ( $95 \%$ Confidence interval) & $p$-value \\
\hline \multicolumn{3}{|l|}{ Marital status } \\
\hline Married & $1.25(0.76-2.23)$ & 0.350 \\
\hline Not married & 1 & \\
\hline \multicolumn{3}{|l|}{ Education } \\
\hline No formal education & 1 & \\
\hline Primary & $1.32(0.95-1.98)$ & 0.071 \\
\hline Post-primary & $3.03(1.23-5.79)$ & $0.043^{*}$ \\
\hline \multicolumn{3}{|l|}{ Occupation } \\
\hline Unemployed & 1 & \\
\hline Employed & $4.13(1.83-8.15)$ & $0.020^{*}$ \\
\hline \multicolumn{3}{|l|}{ Partner disclosure } \\
\hline No & 1 & \\
\hline Yes & $2.53(0.99-5.80)$ & $0.035^{*}$ \\
\hline \multicolumn{3}{|l|}{ Previous PMTCT } \\
\hline No & 1 & \\
\hline Yes & $2.17(1.11-3.03)$ & 0.220 \\
\hline \multicolumn{3}{|l|}{ Treatment support } \\
\hline No & 1 & \\
\hline Yes & $2.15(0.77-4,15)$ & $0.014^{*}$ \\
\hline \multicolumn{3}{|l|}{ РMTCT } \\
\hline No & 1 & \\
\hline Yes & $3.15(0.93-6.21)$ & $0.035^{*}$ \\
\hline \multicolumn{3}{|l|}{ Stigmatisation } \\
\hline No & 1 & \\
\hline Yes & $0.78(0.23-2.45)$ & 0.430 \\
\hline
\end{tabular}

studies. ${ }^{[6,13,26]}$ This is because status disclosure increases social and psychological support for the infected partners, especially from their spouses. This is further supported by another finding of this study that revealed that women who had treatment support from their relatives including their spouses had almost three times higher odds of adherence to their ARV drug regimen compared with women without support. Previous studies have shown that disclosure of status to partners, family and friends not only guaranteed their support but also resulted in their serving as treatment partners by encouraging them, and this was associated with good maternal adherence and improved clinical outcome. ${ }^{[6,13,19]}$ HIV-positive women should be counselled and encouraged to disclose their status, although this should be voluntary because of the risk of intimate partner violence. ${ }^{[13]}$

The use of ARV drugs for PMTCT of HIV infection was a significant determinant of good adherence in this study. It is therefore not surprising that all the women who had good adherence gave this reason as one of their motivating factors, and they had three times higher odds of adherence than the others. It is probable that these women heard and understood during their adherence counselling that ART during pregnancy is not solely for treating maternal disease but also to prevent infection of their unborn babies. The need for continual adherence counselling in this regard cannot be emphasised enough ${ }^{[6]}$ because some of the women with poor adherence in this study missed taking their drugs because they felt better.

Marital status, previous PMTCT experience and HIV stigmatisation were not significantly associated with good adherence on logistic regression analysis. The role of marital status in adherence has been inconsistent, with some previous studies revealing a significant association and others not. ${ }^{[27,28]}$ Previous PMTCT experience was not an independent determinant of good adherence; this was in contrast to reports from Omonaiye et al. ${ }^{[20]}$ and Murithi et al. ${ }^{[29]}$ Both studies found that women who had previously accessed PMTCT successfully (had children who were HIV-negative) were 
better prepared and more adherent to their ARV drug regimen in the current pregnancy. ${ }^{[20,29]}$ Although not significantly associated with adherence, stigmatisation and discrimination remain important factors for non-adherence to ARV drugs because more than half of the women missed their drugs as a result of this. Ekama et al. ${ }^{[13]}$ opined that continual campaigning against stigmatisation and discrimination should be sustained to achieve improved uptake of HIV services and optimal medication adherence.

Women with good adherence in this study reported that their previous PMTCT exposure, living healthily and the desire to protect their unborn baby motivated them to use their ARV drugs. These were also reported in previous studies. ${ }^{[13]}$ Forgetfulness, busy work schedule, feeling better, side-effects of the drugs and stigmatisation were some of the reasons given by the women who had poor adherence. Similar reasons for non-adherence have also been reported in previous studies. ${ }^{[10,13,15,30]}$

Strengths of this study included the fact that it was a multicentre study done in primary and tertiary healthcare centres, and two methods were used in the assessment of adherence among the women, thereby increasing the reliability of the findings. The women's CD4 counts and viral loads, which are used to monitor the progress of the disease, were also measured to correlate their level of adherence. However, the study might be limited by recall bias on the part of the women and the non-use of ARV blood measurement to determine the actual plasma concentration of the ARVs.

\section{Conclusions}

This study revealed good adherence in the majority of the HIVpositive pregnant women. A small proportion of them had poor adherence owing to busy work schedule, forgetfulness, feeling better and fear of stigmatisation. Higher education level, being employed, status disclosure, treatment support and the use of ARV drugs for PMTCT were significant determinants of good adherence. Continual counselling on adherence and partner disclosure should be ensured and sustained for all pregnant women on ARVs for maximum benefit and elimination of the risks of MTCT. A longitudinal study will be desirable in future research to follow up babies that are born to these women to evaluate the effectiveness of adherence on PMTCT of HIV.

\section{Declaration. None.}

Acknowledgements. The authors acknowledged all the women that participated in the study, the trained research assistants and the nursing staff of the antenatal clinics of the Comprehensive Health Centre and Ekiti State University Teaching Hospital, Ado-Ekiti, who assisted in administering the questionnaires. Author contributions. OPA conceptualised and designed the study, and wrote the first draft of the manuscript. TA designed the study, analysed the data and revised the manuscript for intellectual content. IPA collected and analysed the data as well as revising the manuscript for intellectual content. AAA wrote the second draft and revised the manuscript for intellectual content. All authors approved the final version of the manuscript.

Funding. None.

Conflicts of interest. None.
1. Joint United Nations Programme for HIV/AIDS. UNAIDS data 2017. UNAIDS: Geneva, Switzerland.2017 https://www.unaids.org/en/resources/documents/2017/2017_data_book (accessed 11 July 2020).

2. UNAIDS. Global HIV \& AIDS statistics - 2018 Fact Sheet, 2018. https://www.unaids.orgs/sites/ default/files/media_asset/UNAIDS_FactSheet_en.pdf (accessed 11 July 2020).

3. National Agency for the Control of AIDS. Nigeria HIV/AIDS Indicator and Impact Survey (NAIIS) Preliminary findings. NACA 2019 https://www.naiis.ng>resource PDF (accessed 11 July 2020).

4. Omonaiye $\mathrm{O}$, Kusljic $\mathrm{S}$, Nicholson $\mathrm{P}$, Manias E. Medication adherence in pregnant women with human immunodeficiency virus receiving antiretroviral therapy in sub-Saharan Africa: A systematic review. BMC Public Health 2018;18:805 https://doi.org/10.1186/s12889-018-5651-y

5. Ajayi AI, Awopegba OF, Owolabi EO, Ajala A. Coverage of HIV testing among pregnant women in Nigeria: Progress, challenges and opportunities. I Public Health (Oxf) 2019;1-8. https://doi org/10.1093/pubmed/fdz152

6. Igwegbe AO, Ugboaja JO, Nwajiaku LA. Prevalence and determinants of non-adherence to antiretroviral therapy among HIV-positive pregnant women in Nnewi, Nigeria. Int J Med Med Sci 2010;2(8):238-246.

7. Mbengue MAS, Sarr SO, Diop A, Ndour CT, Ndiaye B, Mboup S. Prevalence and determinants of adherence to antiretroviral treatment among HIV patients on first-line regimen: A cross-sectional study in Dakar, Senegal. Pan Afr Med J 2019;33:95. https://doi.org/10.11604/pamj.2019.33.95.17248

8. Xing H, Ruan Y, Li J, et al. HIV drug resistance and its impact on antiretroviral therapy in Chinese HIV infected patients. PLoS One 2013;8. https://doi.org/10.1371/journal.pone.0054917

9. Sears K, Scobie A, Mackinnon NJ. Patient-related risk factors for self-reported medication errors in hospital and community settings in 8 countries. Can Pharm J 2012;145:88-93. https://doi. org/10.3821/145.2.cpj88

10. Olowookere, SA, Fatiregun A, Akinyemi JO, Bamgboye AE, Osagbemi GK. Prevalence and determinants of non-adherence to highly active antiretroviral therapy among people living with HIV/AIDS in Ibadan, Nigeria. J Infect Dev Ctries 2008;2(5):369-372. https://doi.org/10.3855/jidc.199

11. Shaahu VN, Lawoyin TO, Sangowawa AO. Adherence to highly active antiretroviral therapy (HAAT) at a Federal Medical Centre. Afr J Med Med Sci 2008;37(1):29-36.

12. Iliyasu Z, Kabir M, Abubakar IS, Babashani M, Zubair ZA. Compliance to antiretroviral therapy among AIDS patients in Aminu Kano Teaching Hospital, Kano, Nigeria. Niger J Med 2005;14(3):290-294.

13. Ekama SO, Herbertson EC, Addeh EJ, et al. Pattern and determinants of antiretroviral drug adherence among Nigerian pregnant women. J Pregnancy 2012;2012:851810.s. https://doi. org/10.1155/2012/851810

14. Agboeze J, Onwe EO, Onoh R, Nwali IM, Ukaegbe C, Adeoye I. Determinants of adherence to antiretroviral therapy among HIV-positive women accessing prevention of mother to child transmission services in Ebonyi State, Nigeria. Ann Med Health Sci Res 2018;8:248-253.

15. Shibabaw W, Melkam W, Shiabbaw A. Adherence to anti-retroviral therapy among HIV positive pregnant women in Ayder Referral Hospital, Northern Ethiopia. J Antivir Antiretrovir 2018;10:18-22. pregnant women in Ayder Referral Hospital
https://doi.org/10.4172/1948-5964.1000

16. US President's Emergency Plan for AIDS Relief (PEPFAR), Nigeria Country Operational Plan (COP) 2017 Strategic Direction Summary. https://www.pepfar.gov/documents/organization/272254.pdf. (accessed 15 July 2020).

17. Olusanya $\mathrm{O}$, Okpere E, Ezimokhai $\mathrm{M}$. The importance of social class in voluntary fertility control in a developing country. West Afr J Med 1985;4:205-215.

18. Morisky DE, Ang A, Krousel-Wood M, Ward HJ. Predictive validity of a medication adherence measure in an outpatient setting. J Clin Hypertens 2008;10(5):348-354. https://doi.org/10.1111/j.1751measure in an outpation

19. Zacharius KM, Basinda N, Marwa K, Mtui EH, Kalolo A, Kapesa A. Low adherence to Option B antiretroviral therapy among pregnant women and lactating mothers in eastern Tanzania. PLoS ONE 2019;14(2):e0212587. https://doi.org/10.1371/journal.pone. 0212587

20. Omonaiye O, Kusljic S, Nicholson P, Mohebbi M, Manias E. Post Option B+ implementation programme in Nigeria: Determinants of adherence of antiretroviral therapy among pregnant women with HIV. Int J Infect Dis 2019;81:225-230. https://doi.org/10.1016/j.ijid.2019.02.014

21. Ngambi WF, Tweya H, Speight C, et al. Determinant of antiretroviral treatment adherence among women accessing PMTCT "Option B+": A retrospective study of Bwaila Hospital, Malawi. $7^{\text {th }}$ IAS women accessing PMTCT "Option B+": A retrospective study of Bwaila Hospital, Malawi. $7^{\text {th }}$ IAS
Conference on HIV Pathogenesis, Treatment and Prevention, Kuala Lumpur 2013;30. Is there a web Conference on HIV Pathoge
address for the conference?

22. Sarna A, Pujari S, Sengar AK, Garg R, Gupta I, Dam J. Adherence to antiretroviral therapy and its determinants amongst HIV patients in India. Indian J Med Res 2008;127(1):28-38

23. The World Bank. Successful approaches to improving maternal health outcomes. http://go.worldbank. org/0K8ELL1EU0 (accessed 31 July 2020).

24. Aduloju OP, Akintayo AA, Aduloju T, Akin-Akintayo OO. Birth preparedness and complication readiness among antenatal attendees in a teaching hospital in southwest Nigeria. Int J Gynaecol Obstet 2017;139:202-210. https://doi.org/10.1002/ijgo.12271

25. UNAIDS. Counseling and HIV/AIDS: UNAIDS Technical Update (UNAIDS best practices collection: Technical Update). Geneva. https://data.unaids.org/publications (accessed 31 July 2020).

26. Ebuy H, Yebyo H, Alemayehu M. Level of adherence and predictors of adherence to the Option B+ PMTCT programme in Tigray, northern Ethiopia. Int J Infect Dis 2015;33:123-129.

27. Esther B, Rose N, Aggrey M, et al. Facilitators and barriers to uptake and adherence to lifelong antiretroviral therapy among HIV infected pregnant women in Uganda: A qualitative study. BMC Pregnancy Childbirth 2017;17:94. https://doi.org/10.1186\%2Fs12884-017-1276-x

28. Chime OH, Arinze-Onyia SU, Obionu CN. Do peer support groups influence medication adherence? A study among people living with HIV/AIDS in Enugu State, Nigeria. Proc Singap Healthc 2018;27(4). https://doi.org/10.1177\%2F2010105818760923

29. Murithi LK, Masho SW, Vanderbilt AA. Factors enhancing utilisation of and adherence to prevention of mother to child transmission (PMTCT) service in an urban setting in Kenya. AIDS Behav 2015;19(4):645-654. https://doi.org/10.1007/s10461-014-0939-0

30. Kahsay A, Gebeegzziabilier G. Assessment of level of adherence to antiretroviral therapy among adult HIV infected person in Mikelle Hospital, Northern Ethiopia. Clin Med Res 2015;4:50-57. 